\title{
Author Correction: Specific microRNAs Regulate Heat Stress Responses in Caenorhabditis elegans
}

\section{Camilla Nehammer ${ }^{1}$, Agnieszka Podolska ${ }^{1}$, Sebastian D. Mackowiak ${ }^{2}$, Konstantinos Kagias ${ }^{1}$ \& Roger Pocock ${ }^{1,3}$}

Correction to: Scientific Reports https://doi.org/10.1038/srep08866, published online 9 March 2015.

This Article contains errors.

The raw sequencing data was not originally included with the article and is no longer available. The pre-processed data with a description of processing is now publicly deposited. As such, the corrected Data Availability section should read:

\section{Data Availability}

The pre-processed sequencing data and the description of the processing are included in files deposited with Open Science Framework and is available at https://osf.io/7t8j9.

(i) Open Access This article is licensed under a Creative Commons Attribution 4.0 International License, which permits use, sharing, adaptation, distribution and reproduction in any medium or format, as long as you give appropriate credit to the original author(s) and the source, provide a link to the Creative Commons license, and indicate if changes were made. The images or other third party material in this article are included in the article's Creative Commons license, unless indicated otherwise in a credit line to the material. If material is not included in the article's Creative Commons license and your intended use is not permitted by statutory regulation or exceeds the permitted use, you will need to obtain permission directly from the copyright holder. To view a copy of this license, visit http://creativecommons.org/licenses/by/4.0/.

(C) The Author(s) 2019

\footnotetext{
${ }^{1}$ Biotech Research and Innovation Centre, University of Copenhagen, Ole Maaløes Vej 5, Copenhagen, Denmark. ${ }^{2}$ Max-Delbrück-Center for Molecular Medicine, Robert-Rössle-Straße 10, 13125, Berlin, Germany. ${ }^{3}$ Department of Anatomy and Developmental Biology, Faculty of Biomedical and Psychological Sciences, Monash University, Clayton, Victoria, Australia. Camilla Nehammer and Agnieszka Podolska contributed equally. Correspondence and requests for materials should be addressed to R.P. (email: roger.pocock@monash.edu)
} 